\title{
Association Between Overactive Bladder and Polyneuropathy in Diabetic Patients
}

\author{
Nermin Tanik ${ }^{1}$, Serhat Tanik ${ }^{2}$, Sebahattin Albayrak², Kürsat Zengin ${ }^{2}$, Levent Ertugrul Inan ${ }^{1}$, Emel Kiyak Caglayan ${ }^{3}$, \\ Asuman Celikbilek ${ }^{1}$, Kadir Kirboga ${ }^{4}$, Mesut Gurdal ${ }^{2}$ \\ ${ }^{1}$ Department of Neurology, Bozok University Medical School, Yozgat, Turkey \\ ${ }^{2}$ Department of Urology, Bozok University Medical School, Yozgat, Turkey \\ ${ }^{3}$ Department of Obstetrics and Gynecology, Bozok University Medical School, Yozgat, Turkey \\ ${ }^{4}$ Department of Ophthalmology, Bozok University Medical School, Yozgat, Turkey
}

Purpose: Diabetes mellitus (DM) is a chronic metabolic disorder that often leads to complications. We aimed to correlate two complications of DM, polyneuropathy and hyperactive bladder syndrome, using noninvasive measures, such as screening tests.

Methods: We included 80 female and 40 male type 2 diabetic patients in this prospective study. Diabetic polyneuropathy evaluations were conducted using the Douleur Neuropathique 4 Questions (DN4), and overactive bladder (OAB) evaluations were performed using the Overactive Bladder Questionnaire (OAB-V8). The patients were also evaluated for retinopathy and nephropathy. The diabetic male and female patients with or without OAB were chosen and compared for microvascular complications (polyneuropathy, retinopathy, and nephropathy).

Results: There were no significant correlations between $\mathrm{OAB}$ and retinopathy as well as between $\mathrm{OAB}$ and nephropathy among diabetic patients (female patients, $\mathrm{P}>0.05$; male patients, $\mathrm{P}>0.05$ ). However, the patients with $\mathrm{OAB}$ were significantly more likely to develop polyneuropathy (female patients, $\mathrm{P}<0.05$; male patients, $\mathrm{P}<0.05$ ).

Conclusions: In diabetic patients, $\mathrm{OAB}$ and diabetic peripheral neuropathy are significantly correlated. These correlations were demonstrated using short, understandable, valid, and reliable disease-specific tests without invasive measures. Using these screening tests, both neurologists and urologists can easily diagnose these complications.

Keywords: Diabetic Neuropathies; Urinary Bladder, Overactive; Screening Tests

- Research Ethics: This work was approved by the Ethics Committee of Bozok University, Medicine Faculty (13.03.2015/79), and all patients provided written informed consent.

- Conflict of Interest: No potential conflict of interest relevant to this article was reported.

\section{INTRODUCTION}

Diabetes mellitus (DM) is a chronic disease that can lead to many complications, including peripheral sensorimotor polyneuropathy, which is very common [1]. The distal lower ex- tremities are predominantly affected. If the disease progresses, sensory loss proceeds proximally, eventually affecting the hands. The incidence of peripheral neuropathy was reported at 5\%-71\% [2].

Diabetic bladder dysfunction (DBD), which commonly ac-

Corresponding author: Nermin Tanik (D) http://orcid.org/0000-0002-7567-9244 Department of Neurology, Bozok University Medical School, 66200, Yozgat, Turkey

E-mail: drnermin27@hotmail.com / Tel: +90-505-950-4844 / Fax: +90-354-217-7150

This is an Open Access article distributed under the terms of the Creative Commons Attribution Non-Commercial License (http://creativecommons.org/licenses/by-nc/4.0/) which permits unrestricted non-commercial use, distribution, and reproduction in any medium, provided the original work is properly cited.

Submitted: February 4, 2016 / Accepted after revision: February 16, 2016 
companies DM. The most common defined bladder dysfunction is detrusor overactivity (DO) with and without impaired detrusor contractility. Its prevalence is reported at $25 \%-87 \%$ [3]. Studies have shown that overactive bladder (OAB) disorder is associated with storage symptoms (e.g., urinary urgency with or without urinary incontinence, usually with increased urinary frequency and nocturia) [4-6]. OAB affects $39 \%-61 \%$ of diabetic patients $[7,8]$.

Correlation between bladder dysfunction and the peripheral nervous system has been demonstrated in many studies [9-11]. These studies used urodynamic tests to diagnose DBD and neurophysiological tests to diagnose diabetic polyneuropathy. We used the Douleur Neuropathique 4 Questions (DN4) and the Overactive Bladder Questionnaire (OAB-V8) to identify the correlations between diabetic polyneuropathy and $\mathrm{OAB}$. We aimed to determine the correlations between these conditions using noninvasive, short, easily applicable, valid, and reliable tests.

\section{MATERIALS ANS METHODS}

\section{Study Population}

This prospective study included 80 female and 40 male patients for a total of 120 patients with type $2 \mathrm{DM}$. The patients with benign prostatic hyperplasia, malignancies, urinary tract infections, a history of major pelvic surgery, pelvic organ prolapse, major neurologic diseases (e.g., Parkinson, Alzheimer, or cerebrovascular disease), chronic renal or hepatic disease, and vitamin B12 deficiency, as well as those taking diuretics were excluded from the study. DM was diagnosed according to the American Diabetes Association Criteria [12]. According to the World Health Organization classification, the body mass indices (BMIs) were calculated using the patients' height and weight measurements [13]. Routine hematological and biochemical analyses were performed on venous blood samples between 9:00 AM and 10:00 AM after an overnight fast.

This work was approved by the Ethics Committee of Bozok University, Medicine Faculty (13.03.2015/79), and all patients provided written informed consent.

\section{Assessment of Peripheral Neuropathy}

To diagnose polyneuropathy, the DN4 was used (Supplementary material). The DN4 is a clinician-administered questionnaire containing 7 items related to symptoms and 3 items related to neuropathic pain examination. The total score is calculated as the sum of the 10 items, and a total score of 4 or more suggests neuropathic pain. The DN4 showed 83\% sensitivity and 90\% specificity in the diagnosis of neuropathic pain in a developmental study [14]. The DN4 Turkish version has been validated [15].

\section{Assessment of OAB}

For the diagnosis of OAB, the OAB-V8 was applied. This commonly used form consists of eight questions with a total score of 40. The Turkish version was validated and subjects with 11 points or higher was accepted as OAB [16].

\section{Assessment of Retinopathy}

All patients underwent ocular examination by the same ophthalmologist. Retinopathy was defined as the presence of characteristic changes, including hemorrhages, exudates, laser marks, and fibrous proliferation, detected by ophthalmoscopy through dilated pupils. Diabetic retinopathy is classified as either nonproliferative or proliferative diabetic retinopathy [17].

\section{Assessment of Nephropathy}

The estimated glomerular filtration rate was calculated using the Cockcroft-Gault equation. The albumin secretion rate was calculated using the albumin: creatine ratio in the urine. Microalbuminuria ( $\geq 30 \mathrm{mg}$ ) and macroalbuminuria (>300 mg) were diagnosed based on the urinary albumin:creatinine ratio [18].

\section{Statistical Analysis}

The SPSS ver. 16 (SPSS Inc., Chicago, IL, USA) was used for statistical analysis. The age, duration of diabetes, BMI, routine hematological and biochemical analyses were reported as the mean \pm standard error. The independent sample t-test was used to compare the differences between continuous variables, while Chi-square analysis was used to assess the differences between categorical variables. P-values $<0.05$ were considered to indicate statistical significance.

\section{RESULTS}

The demographic and laboratory data of all diabetic patients are shown in Table 1. Diabetic female patients with and without $\mathrm{OAB}$ were compared according to microvascular complications (polyneuropathy, retinopathy, and nephropathy) (Table 2). There were no significant correlations between $\mathrm{OAB}$ and reti- 
nopathy as well as between $\mathrm{OAB}$ and nephropathy among female patients $(\mathrm{P}>0.05)$. There was a significant correlation between $\mathrm{OAB}$ and polyneuropathy among female patients $(\mathrm{P}<0.05)$. Male patients with and without $\mathrm{OAB}$ were compared according to microvascular complications (polyneuropathy,

Table 1. Demographic and laboratory data of diabetic patients $(\mathrm{n}=120)$

\begin{tabular}{lc}
\hline Variable & Value \\
\hline Age $(\mathrm{yr})$ & $57.26 \pm 10.09$ \\
Sex & \\
Female & $80(66.7)$ \\
Male & $40(33.3)$ \\
Disease duration $(\mathrm{yr})$ & $8.75 \pm 7.54$ \\
Body mass index $\left(\mathrm{kg} / \mathrm{m}^{2}\right)$ & $32.67 \pm 5.23$ \\
HbAlc $(\%)$ & $8.38 \pm 1.93$ \\
White blood cell $\left(10^{3} / \mathrm{mm}^{3}\right)$ & $8.29 \pm 2.09$ \\
Hemoglobin $(\mathrm{mg} / \mathrm{dL})$ & $13.66 \pm 1.54$ \\
Platelet $\left(10^{3} / \mathrm{mm}{ }^{3}\right)$ & $258.02 \pm 65.35$ \\
Fasting glucose $(\mathrm{mg} / \mathrm{dL})$ & $198.80 \pm 89.98$ \\
Creatinine $(\mathrm{mg} / \mathrm{dL})$ & $0.77 \pm 0.19$ \\
Aspartate aminotransferase $(\mathrm{IU} / \mathrm{L})$ & $23.54 \pm 14.68$ \\
Alanine aminotransferase $(\mathrm{IU} / \mathrm{L})$ & $26.95 \pm 18.52$ \\
Total cholesterol $(\mathrm{mg} / \mathrm{dL})$ & $208.06 \pm 48.74$ \\
Triglyceride $(\mathrm{mg} / \mathrm{dL})$ & $188.25 \pm 118.14$ \\
HDL-C $(\mathrm{mg} / \mathrm{dL})$ & $44.28 \pm 12.86$ \\
LDL-C $(\mathrm{mg} / \mathrm{dL})$ & $130.51 \pm 36.10$ \\
\hline
\end{tabular}

Values are presented as mean \pm standard error or number (\%). HbA1c, glycosylated hemoglobin A1c; HDL-C, high-density lipoprotein cholesterol; LDL-C, low-density lipoprotein cholesterol. retinopathy, and nephropathy). There were no significant correlations between $\mathrm{OAB}$ and retinopathy as well as between $\mathrm{OAB}$ and nephropathy among male patients $(\mathrm{P}>0.05)$. There was a significant correlation between $\mathrm{OAB}$ and polyneuropathy among male patients $(\mathrm{P}<0.05)$ (Table 3$)$.

\section{DISCUSSION}

This study revealed two significant findings. First, there is a significant correlation between $\mathrm{OAB}$ and diabetic peripheral neuropathy among diabetic patients. More importantly, this correlation was shown using noninvasive, short, and technically simple screening tests. Second, this correlation was not found in other microvascular complications of diabetes, such as retinopathy and nephropathy.

Most cases of diabetic neuropathy present in a distally symmetrical form due to progressive axonopathy.

Sensory symptoms precede motor symptoms in diabetic polyneuropathy. The function of small fibers (C-fibers without myelin and A-gamma with thin myelin) is affected in the early stages of DM. Large fibers (thick myelinated A-alpha and A-beta) are not affected [19]. No standard diagnostic criteria exist for small fiber neuropathy. Standard nerve conduction studies involving electromyography (EMG) do not help diagnose small fiber neuropathy. A neurophysiologic test that records sympathetic skin responses is sometimes used, but the responses are unreliable and the sensitivity is low for small fiber neuropathy [20]. Quantitative sensation tests (vibration, hot-cold, and thermal pain level) require patient cooperation, and an abnormal test result does not necessarily indicate a peripheral nervous

Table 2. Comparisons of microvascular complications between diabetic women with and without overactive bladder (OAB) syndrome $(\mathrm{n}=80)$

\begin{tabular}{lccc}
\hline Variable & OAB syndrome & Without OAB syndrome & P-value \\
\hline No. of patients & $26(32.5)$ & $54(67.5)$ & \\
Polyneuropathy & & & $0.003^{*}$ \\
$\quad$ With & $22(27.5)$ & $27(33.8)$ & \\
$\quad$ Without & $4(5.0)$ & $27(33.8)$ & 0.763 \\
Retinopathy & $5(6.3)$ & $9(11.3)$ & \\
$\quad$ With & $21(26.3)$ & $45(56.3)$ & 0.572 \\
$\quad$ Without & $7(8.8)$ & $11(13.8)$ & \\
Nephropathy & $19(23.8)$ & $43(53.8)$ & \\
$\quad$ With & & & \\
Without & &
\end{tabular}

Values are presented as number (\%).

${ }^{*} \mathrm{P}<0.05$, statistically significant difference. 
Table 3. Comparisons of microvascular complications between diabetic men with and without overactive bladder (OAB) syndrome $(\mathrm{n}=40)$

\begin{tabular}{|c|c|c|c|}
\hline Variable & OAB syndrome & Without OAB syndrome & P-value \\
\hline No. of patients & $14(35.0)$ & $26(65.0)$ & \\
\hline $\begin{array}{l}\text { Polyneuropathy } \\
\text { With } \\
\text { Without }\end{array}$ & $\begin{array}{c}11(27.5) \\
3(7.5)\end{array}$ & $\begin{array}{l}10(25.0) \\
16(40.0)\end{array}$ & $0.022^{*}$ \\
\hline $\begin{array}{l}\text { Retinopathy } \\
\text { With } \\
\text { Without }\end{array}$ & $\begin{array}{c}3(7.5) \\
11(27.5)\end{array}$ & $\begin{array}{c}1(2.5) \\
25(62.5)\end{array}$ & 0.115 \\
\hline $\begin{array}{l}\text { Nephropathy } \\
\text { With } \\
\text { Without }\end{array}$ & $\begin{array}{l}8(20.0) \\
6(15.0)\end{array}$ & $\begin{array}{r}7(17.5) \\
19(47.5)\end{array}$ & 0.089 \\
\hline
\end{tabular}

Values are presented as number (\%).

${ }^{\star} \mathrm{P}<0.05$, statistically significant difference.

system disorder, as any nervous system disorder can affect the results $[21,22]$. Thus, the tests used to diagnose small fiber neuropathy have only limited applicability.

Many studies have shown that axonopathy and small fiber neuropathy may take part in the early stages of diabetic neuropathy and $\mathrm{OAB}$. Another study showed that axonopathy may cause DBD [23]. In these patients, axonal swelling and degeneration were seen [24]. Other studies have identified defects in A-gamma and $\mathrm{C}$ small fiber bladder afferent neural pathways $[25,26]$. All these findings confirm small fiber autonomic neuropathy in the bladder [27]. Small fiber autonomic neuropathy may increase smooth muscle contractility and detrusor muscle overactivity $[25,26]$. The presentation of peripheral neuropathy is hypersensitvity, hyposensitivity, and anesthesia. It has been proposed that the same type of pathology may lead to OAB [19]. A study in female patients with $O A B$ and diabetes showed DO following bladder oversensitivity [28]. Invasive urodynamic studies, including those involving cystometry, have been used to diagnose bladder dysfunction. Unfortunately, cystometry may not show the pathological changes associated with $\mathrm{OAB}$ in up to $40 \%$ of patients with the condition [29]. Another urodynamic study tool is the uroflowmeter, which can differentiate true obstruction from weak detrusor contractility [30]. For the most part, techniques used for the diagnosis of bladder dysfunction and small fiber neuropathy have limited efficiency, and an accepted set of diagnostic criteria has yet to be formulated.

In a study of 94 diabetic female patients, $\mathrm{OAB}$ was diagnosed in $36.2 \%$ [28]. The incidence of OAB among female patients reported in this study (32.5\%) is similar to that mentioned in the previous study and is consistent with that observed in males (35\%). Lee et al. [9] performed a study that included 137 female diabetic patients who were followed up for 11 years. The authors examined the early stages of autonomic DBD and distal symmetric diabetic neuropathy, and diagnosed polyneuropathy in $67.2 \%$, compared to our finding of $61.3 \%$. Lee et al. [9] used the current perception threshold test for C-fiber functions to diagnose diabetic polyneuropathy. Uroflowmetry, postvoid residual urine volume, and the $\mathrm{OAB}$ symptom score questionnaire were also used. They concluded that C-fiber dysfunction in the distal extremities of female patients may be a marker of early DBD. Bansal et al. [10] studied 52 diabetic male patients with lower urinary tract symptoms (LUTS) and attempted to diagnose combined neuropathy using urodynamic studies, hand and foot sympathetic skin responses, and motor and sensory nerve-conduction velocity studies. They found the condition in $51.9 \%$ of male diabetic patients, compared to our finding of 52.5\%. Therefore, male patients with DM and LUTS are likely to have neuropathy, which, in turn, may probably be associated with DBD. Another study of 29 diabetic patients used peroneal and sural nerve conduction studies and urodynamic and denervation supersensitivity tests and found meaningful correlations with vesicourethral dysfunction and peripheral neuropathy [11]. Neuropathy was found in $69 \%$ of patients with voiding dysfunction. We found polyneuropathy in $84.6 \%$ of female patients and $78.6 \%$ of male patients with voiding dysfunction. The polyneuropathy ratio found in this study was higher than that of the mentioned study, which may be due to the failure to detect small fiber neuropathy using EMG. In a previous study of 153 type 2 diabetic patients with LUTS symp- 
toms, sensory thresholds (vibratory, thermal, and touch) and uroflowmetry were used. That study concluded that neuropathy is a predictor of bladder dysfunction [31]. In our study, we found $\mathrm{OAB}$ in $44.9 \%$ of female patients and $52.4 \%$ of male patients with polyneuropathy. These findings support those of the mentioned study.

Our study's results regarding the relationship between diabetic polyneuropathy and $\mathrm{OAB}$ using screening tests were similar to those that used urodynamic and neurophysiologic tests, which supported the reliability of the screening tests. We used DN4 to diagnose diabetic polyneuropathy. Linguistic validation of the DN4 for use in international studies has been reported as well [32]. We concluded that the validated Turkish version of the DN4 is a reliable, valid, and fast screening test for detecting neuropathic pain. The DN4 takes only 1 minute to perform and has a sensitivity of $95 \%$ and a specificity of $96.6 \%$ [15]. Painful diabetic neuropathy is also diagnosed using the DN4 test [33]. We used $\mathrm{OAB}-\mathrm{V} 8$ to diagnose $\mathrm{OAB}$, which includes the first 8 questions of the $\mathrm{OAB}$-questionnaire and proposed $\mathrm{OAB}$ screening. Acquadro et al. [34] translated it into 14 languages in 2006 and linguistic validations were completed. The OAB-V8 is a short, efficient, and usable screening tool, and the validity of its Turkish version has been demonstrated [16].

In conclusion, we found that there is significant correlation between $\mathrm{OAB}$ and diabetic peripheral neuropathy among DM patients by using noninvasive, short, and easily applicable questionnaires. This finding helps improve the understanding of the characteristics of representative DM complications. This correlation might give clinicians a good and early opportunity to evaluate the risk of other DM complications using simple and easy methodologies.

\section{REFERENCES}

1. Doppler K, Reiners K. Diabetic neuropathy: do not only consider distal symmetrical neuropathy. Nervenarzt 2015;86:161-6.

2. Boulton AJ. Guidelines for diagnosis and outpatient management of diabetic peripheral neuropathy. European Association for the Study of Diabetes, Neurodiab. Diabetes Metab 1998;24 Suppl 3:5565 .

3. Kirschner-Hermanns R, Daneshgari F, Vahabi B, Birder L, Oelke M, Chacko S. Does diabetes mellitus-induced bladder remodeling affect lower urinary tract function? ICI-RS 2011. Neurourol Urodyn 2012;31:359-64.

4. Abrams P, Cardozo L, Fall M, Griffiths D, Rosier P, Ulmsten U, et al. The standardisation of terminology of lower urinary tract function: report from the Standardisation Sub-committee of the International Continence Society. Neurourol Urodyn 2002;21:167-78.

5. Yamaguchi C, Sakakibara R, Uchiyama T, Yamamoto T, Ito T, Liu Z, et al. Overactive bladder in diabetes: a peripheral or central mechanism? Neurourol Urodyn 2007;26:807-13.

6. Stewart WF, Van Rooyen JB, Cundiff GW, Abrams P, Herzog AR, Corey R, et al. Prevalence and burden of overactive bladder in the United States. World J Urol 2003;20:327-36.

7. Liu RT, Chung MS, Lee WC, Chang SW, Huang ST, Yang KD, et al. Prevalence of overactive bladder and associated risk factors in 1359 patients with type 2 diabetes. Urology 2011;78:1040-5.

8. Kebapci N, Yenilmez A, Efe B, Entok E, Demirustu C. Bladder dysfunction in type 2 diabetic patients. Neurourol Urodyn 2007;26:8149.

9. Lee WC, Wu HC, Huang KH, Wu HP, Yu HJ, Wu CC. Hyposensitivity of C-fiber afferents at the distal extremities as an indicator of early stages diabetic bladder dysfunction in type 2 diabetic women. PLoS One 2014;9:e86463.

10. Bansal R, Agarwal MM, Modi M, Mandal AK, Singh SK. Urodynamic profile of diabetic patients with lower urinary tract symptoms: association of diabetic cystopathy with autonomic and peripheral neuropathy. Urology 2011;77:699-705.

11. Mitsui T, Kakizaki H, Kobayashi S, Morita H, Matsumura K, Koyanagi T. Vesicourethral function in diabetic patients: association of abnormal nerve conduction velocity with vesicourethral dysfunction. Neurourol Urodyn 1999;18:639-45.

12. American Diabetes Association. Standards of medical care in diabetes: 2013. Diabetes Care 2013;36 Suppl 1:S11-66.

13. Physical status: the use and interpretation of anthropometry. Report of a WHO Expert Committee. World Health Organ Tech Rep Ser 1995;854:1-452.

14. Bouhassira D, Attal N, Alchaar H, Boureau F, Brochet B, Bruxelle J, et al. Comparison of pain syndromes associated with nervous or somatic lesions and development of a new neuropathic pain diagnostic questionnaire (DN4). Pain 2005;114:29-36.

15. Unal-Cevik I, Sarioglu-Ay S, Evcik D. A comparison of the DN4 and LANSS questionnaires in the assessment of neuropathic pain: validity and reliability of the Turkish version of DN4. J Pain 2010;11:112935.

16. Tarcan T, Mangir N, Ozay O, Akbal C. OAB-V8 overactive bladder questionnaire validation study. Üroloji Bülteni 2012;21:113-6.

17. The effect of intensive treatment of diabetes on the development and progression of long-term complications in insulin-dependent diabetes mellitus. The Diabetes Control and Complications Trial 
Research Group. N Engl J Med 1993;329:977-86.

18. Chandy A, Pawar B, John M, Isaac R. Association between diabetic nephropathy and other diabetic microvascular and macrovascular complications. Saudi J Kidney Dis Transpl 2008;19:924-8.

19. Said G. Diabetic neuropathy: a review. Nat Clin Pract Neurol 2007; 3:331-40.

20. Lacomis D. Small-fiber neuropathy. Muscle Nerve 2002;26:173-88.

21. Magda P, Latov N, Renard MV, Sander HW. Quantitative sensory testing: high sensitivity in small fiber neuropathy with normal NCS/EMG. J Peripher Nerv Syst 2002;7:225-8.

22. Freeman R, Chase KP, Risk MR. Quantitative sensory testing cannot differentiate simulated sensory loss from sensory neuropathy. Neurology 2003;60:465-70.

23. Steers WD, Mackway-Gerardi AM, Ciambotti J, de Groat WC. Alterations in neural pathways to the urinary bladder of the rat in response to streptozotocin-induced diabetes. J Auton Nerv Syst 1994; 47:83-94.

24. Mastri AR. Neuropathology of diabetic neurogenic bladder. Ann Intern Med 1980;92(2 Pt 2):316-8.

25. Yoshimura N, Chancellor MB, Andersson KE, Christ GJ. Recent advances in understanding the biology of diabetes-associated bladder complications and novel therapy. BJU Int 2005;95:733-8.

26. Sasaki K, Yoshimura N, Chancellor MB. Implications of diabetes mellitus in urology. Urol Clin North Am 2003;30:1-12.

27. Van Poppel H, Stessens R, Van Damme B, Carton H, Baert L. Dia- betic cystopathy: neuropathological examination of urinary bladder biopsies. Eur Urol 1988;15:128-31.

28. Ho $\mathrm{CH}$, Tai HC, Yu HJ. Urodynamic findings in female diabetic patients with and without overactive bladder symptoms. Neurourol Urodyn 2010;29:424-7.

29. McGuire EJ. Urodynamic evaluation of stress incontinence. Urol Clin North Am 1995;22:551-5.

30. Chancellor MB, Blaivas JG, Kaplan SA, Axelrod S. Bladder outlet obstruction versus impaired detrusor contractility: the role of outflow. J Urol 1991;145:810-2.

31. Karoli R, Bhat S, Fatima J, Priya S. A study of bladder dysfunction in women with type 2 diabetes mellitus. Indian J Endocrinol Metab 2014;18:552-7.

32. Van Seventer R, Vos C, Meerding W, Mear I, Le Gal M, Bouhassira $\mathrm{D}$, et al. Linguistic validation of the DN4 for use in international studies. Eur J Pain 2010;14:58-63.

33. Miralles-Garcia JM, de Pablos-Velasco P, Cabrerizo L, Perez M, Lopez-Gomez V; Sociedad Española de Endocrinología y Nutrición. Prevalence of distal diabetic polyneuropathy using quantitative sensory methods in a population with diabetes of more than 10 years' disease duration. Endocrinol Nutr 2010;57:414-20.

34. Acquadro C, Kopp Z, Coyne KS, Corcos J, Tubaro A, Choo MS, et al. Translating overactive bladder questionnaires in 14 languages. Urology 2006;67:536-40. 
Supplementary Materıal. Douleur Neuropathique 4 Questions (DN4) questionnaire

Please complete this questionnaire by ticking one answer for each item in the 4 questions below.

Interview of the patient

Question 1: Does the pain have one or more of the following characteristics?
1. Burning
$\bigcirc$ Yes
No
2. Painful cold
$\bigcirc$ Yes
No
3. Electric shocks
$\bigcirc$ Yes
No

Question 2: Is the pain associated with one or more of the following symptoms in the same area?
4. Tingling
$\bigcirc$ Yes
No
5. Pins and needles
$\bigcirc$ Yes
No
6. Numbness
$\bigcirc$ Yes
$\mathrm{No}$
7. Itching
$\bigcirc$ Yes
No

\section{Examination of the patient}

Question 3: Is the pain located in an area where the physical examination may reveal one or more of the following characteristics?
8. Hypoesthesia to touch
$\bigcirc$ Yes
No
9. Hypoesthesia to prick
$\bigcirc$ Yes
No

Question 4: In the painful area, can the pain be caused or increased by:
10. Brushing?
$\bigcirc$ Yes
No

\section{To collate:}

- Score 1 to each YES answer

- Score 0 to each NO answer

- If the score is 4 or higher then the pain is likelyto be neuropathic pain.

- If the score is less than 4 then the pain is unlikely to be neuropathic pain. 


\section{OAB Questionnaire}

The questions below ask about how bothered you may be by some bladder symptoms. Some people are bothered by bladder symptoms and may not realize that there are treatments available for their symptoms. Please circle the number that best describes how much you have been bothered by each symptom. Add the numbers together for a total score and write that in the box below the chart.

\begin{tabular}{|lccccc|}
\hline During the past 4 weeks, how bothered were you by: & Not at all & A little bit & Some-what Quite a bit & A great deal A very great deal \\
\hline 1. Frequent urination during daytime hours? & 0 & 1 & 2 & 3 & 4 \\
2. An uncomfortable urge to urinate? & 0 & 1 & 2 & 3 & 4 \\
3. A sudden urge to urinate with little or no warning? & 0 & 1 & 2 & 3 & 4 \\
4. Accidental loss of small amounts of urine? & 0 & 1 & 2 & 3 & 4 \\
5. Night-time urination? & 0 & 1 & 2 & 3 & 4 \\
6. Waking up at night because you had to urinate? & 0 & 1 & 2 & 3 & 4 \\
7. An uncontrollable urge to urinate? & 0 & 1 & 2 & 3 & 4 \\
8. Urine loss associated with a strong desire to urinate? & 0 & 1 & 2 & 3 & 4 \\
Are you a male? If male, add 2 points to your score & & & & 5 \\
\hline
\end{tabular}

Add up your score:

If your score is 8 or greater, you may have overactive bladder. There are effective treatments for this condition. You may want to talk to a healthcare professional about your symptoms. 